\title{
La atenuación y la estructura informativa: el caso de focalización
}

\section{The Attenuation and the Informative Structure: the Focalization Case}

\author{
EwA URBANiAK [ewa.urbaniakowa@gmail.com] \\ Uniwersytet Łódzki, Polonia
}

\begin{abstract}
RESUMEN
La estructura informativa mantiene estrechas relaciones con diversas dimensiones del texto. La estructuración de la información puede resultar esencial a la hora de interpretar el sentido general de determinadas unidades discursivas. Uno de los fenómenos relacionados con el concepto de la organización informativa del texto es la focalización, esto es, el hecho de atraer la atención del receptor a una parte del enunciado. Son varias las operaciones reconocidas como focalizadoras, tanto sintácticas como léxico-semánticas o fonológicas. Como se presenta en el artículo, el procedimiento de la focalización puede actuar también como uno de los mecanismos de atenuación. Analizando una serie de ejemplos se demuestra en qué medida el hecho de resaltar una información u ocultar otra constituye la operación atenuadora.
\end{abstract}

\section{Palabras Clave}

atenuación; estructura informativa; focalización; lingüística pragmática

\begin{abstract}
The informative structures maintain strict relations with different text dimensions. The structure of the information can be essential while interpreting the general meaning of some of the discourse units. One of the informative structure concepts is the focalization, in other words, the act of highlighting one of the parts of the statement. There are several operations that represent the focalization phenomena, some of them are syntactical, the others lexical or phonological. As it presented in the article, the focalization can also be an attenuation mechanism. The analysis of a number of examples demonstrates that the act of highlighting or hiding one information can be perceived as the attenuation mechanism.
\end{abstract}

\section{KEYWORDS}

attenuation; informative structure; focalization; pragmatic linguistics

RECIBIDO 2017-10-15; ACEPTADO 2017-11-24 


\section{Introducción}

El mecanismo de atenuación constituye un componente muy importante a la hora de analizar las conversaciones que llevamos a cabo cada día. Resulta imprescindible para mantener ciertas relaciones con otras personas, o bien para proyectar una determinada imagen de sí mismo. La atenuación nos permite también funcionar en la sociedad evitando situaciones conflictivas o, por lo menos, desagradables. Por eso, creemos tan importante identificar los mecanismos que constituyen fundamentos de este proceso.

El objetivo de nuestro trabajo radica en el reconocimiento de los procedimientos atenuadores, sin embargo, no consideramos como elementos básicos unidades sintácticas o semánticas, sino las unidades informativas. De acuerdo con el modelo de la Lingüística Pragmática de Fuentes Rodríguez (2015), buscamos relaciones no solo entre los recursos lingüísticos y la atenuación, sino entre la información y la atenuación. Como la información se expresa mediante la estructura semántica, sintáctica y fonética, resulta imposible realizar un análisis de la estructura informativa sin mencionar ciertos mecanismos lingüísticos. No obstante, los recursos lingüísticos que investigamos constituyen el fundamento de una unidad de naturaleza bien distinta, esto es, la información.

La estructura informativa acapara una serie de procesos entre los cuales encontramos la focalización. En el presente trabajo buscamos los posibles vínculos entre el fenómeno de la focalización y la estrategia atenuadora. El análisis del corpus nos aporta numerosos ejemplos que, a nuestro juicio, afirman la relación entre la estructura informativa y la atenuación.

\section{La metodología}

En el presente estudio seguimos el modelo de la Lingüística Pragmática propuesto por Catalina Fuentes Rodríguez (2015: 50-56). El modelo divide el texto en tres niveles: la Superestructura (el tipo de texto emitido), la Macroestructura (la organización del texto en párrafos, su estructura argumentativa, informativa y polifónica) y la Microestructura (los recursos fonéticos, morfosintácticos y semánticos). Estas estructuras vienen condicionadas por la situación: son los rasgos extralingüísticos que incitan a los hablantes a elegir un determinado género textual, a organizar el texto de una manera concreta, y además, a recurrir a unos mecanismos lingüísticos adecuados. Aparte de eso, se observa un fuerte vínculo entre las distintas estructuras. A saber, la Superestructura (el tipo de texto) contribuye tanto a la organización interna del texto (la Macroestructura), como a la elección de unos medios lingüísticos (la Microstructura). Por otra parte, es la Macroestructura que determina los mecanismos más apropiados para un texto concreto. Con el objetivo de ilustrar el funcionamiento del modelo de Fuentes Rodríguez analizamos brevemente el texto siguiente: 

(1)
C: oye $\uparrow$ papá
B: ¿qué?
C: ¿has visto la pancarta/esa de ahí?

Situación: comida familiar, informal;

Superestructura: conversación coloquial;

Macroestructura: como es un texto dialogal (Superestructura) constituye un intercambio dividido en tres intervenciones. Además, debido a la situación extralingüística, se configura la estructura informativa del texto, esto es, se plantea cuál es la información nueva, desconocida que constituirá el tema principal de la conversación.

Microestructura: la informalidad de la situación suscita el uso de la segunda persona (y no la forma de tratamiento usted) lo que se manifiesta en la flexión verbal de has visto. Además, la Superestuctura (la estructura del texto dialogal) requiere el uso de distintos elementos fáticos para mantener el contacto entre los interlocutores, como el vocativo en oye, papá o la interrogación ¿qué?. Por otra parte, la estructura informativa (la Macroestructura) requiere un cierto orden de constituyentes, esto es, en el enunciado ¿has visto la pancarta? la pancarta indica la información nueva, por eso va en la posición final (después de has visto), y además, viene especificada por una expresión focalizadora esa de ahí cuya función principal radica en ayudar al interlocutor a identificar el objeto en cuestión.

A lo largo de nuestro análisis seguiremos el modelo expuesto tomando en consideración dos suposiciones:

- entre diversas estructuras de la lengua se hallan unas relaciones bilaterales que ejercen una gran influencia sobre el aspecto final del enunciado;

- los elementos de la Macroestructura se apoyan en determinados mecanismos microestructurales, esto es, para expresar ciertas nociones se necesitan unas unidades lingüísticas concretas.

La atenuación y la focalización son dos representantes de la Macroestructura: la estructura argumentativa y la informativa respectivamente. La dimensión argumentativa del texto radica en aportar por parte del emisor del enunciado una serie de argumentos, apoyados en un topos común para la mayoría de los miembros de una sociedad, con el objetivo de que el destinatario llegue a una conclusión concreta (Fuentes Rodríguez - Alcaide 2007: 9-14) Aunque tradicionalmente atribuida a un determinado tipo de textos (ej. los jurídicos), la argumentación puede constituir una dimensión de todo tipo de discursos, incluso las conversaciones coloquiales (Fuentes Rodríguez - Alcaide 2007: 11-16). Efectivamente, si reflexionamos sobre la naturaleza de los enunciados que emitimos diariamente, una gran parte de los que producimos sirve para influir de una u otra manera al comportamiento o pensamiento de nuestros interlocutores.

En el presente trabajo, el mecanismo argumentativo viene representado por la atenuación. Como afirman Albelda y Briz (2013: 292-293):

1 El ejemplo tomado de Cabedo, Adrián y Pons, Salvador (eds.): Corpus Val.Es.Co 2.0. Consultado online en http://www.valesco.es [30/09/2016] 
Es una estrategia, puesto que se atenúa, argumentativamente hablando, para lograr el acuerdo o aceptación del otro (incluso, cuando esta sea solo una aceptación social). Luego, es un mecanismo retórico para convencer, lograr un beneficio, persuadir y, a la vez, para cuidar las relaciones interpersonales y sociales o evitar que estas sufran algún tipo de menoscabo.

En otras palabras, al atenuar los hablantes intentan obtener alguna finalidad argumentativa. Briz (2003: 21) subraya también que la dimensión argumentativa de la atenuación radica en la "minoración del beneficio del que habla, minoración de su contribución y del posible desacuerdo". El distanciamiento producido en el proceso de atenuar disminuye la discordia entre los hablantes, tan frecuente a la hora de expresar opiniones o juicios.

El segundo concepto del que trata el presente artículo constituye la focalización perteneciente a la estructura informativa del texto. Como afirma Rojo (1983: 75-100), cada enunciado, aparte de su contenido sintáctico y semántico, posee una dimensión informativa independiente de sus rasgos formales o relacionados con el significado. La información se basa en la Sintaxis y en la Semántica (sin ellas no existen los enunciados), sin embargo, es un ente autónomo que se comporta libremente. Si comparamos, por ejemplo, dos enunciados aparentemente iguales, podemos observar la diferencia:

(2) María ha comprado un vestido nuevo.

(3) Un vestido nuevo ha comprado María.

Ambos enunciados se componen de los mismos elementos semánticos y sintácticos, en lo que se diferencian es el contenido informativo. Según el método de la pregunta inicial (Gutiérrez Ordóñez 2014: 20-32), el primer enunciado responde a la pregunta ¿Qué ha comprado María?, mientras que el segundo a ¿Quién ha comprado un vestido nuevo? Observamos así que la información transmitida por los enunciados es diversa.

El mecanismo informativo que constituye el núcleo de nuestro análisis es la focalización. El foco puede tener dos interpretaciones: como una información nueva, o bien como un elemento de carácter paradigmático que destaca una parte del enunciado, no necesariamente el rema (Face 2002; Rodríguez 2005). En el presente trabajo entendemos por la noción de foco la segunda definición. Como advierte Dorta (2008: 119), la focalización puede manifestar los intereses ilocutivos, esto es, apoyar la intención comunicativa (que no siempre coincide con la información nueva). También Gutiérrez Ordóñez (2014: 33-34) define la focalización como el hecho de resaltar una parte de información para llamar la atención del oyente a un fragmento del enunciado. En contraste con la oposición tema/rema, no es una función obligatoria: es la decisión del emisor que condiciona su aparición en el enunciado.

Aunque el proceso de focalización no cambia el contenido informativo, sí que altera su percepción. Comparamos los enunciados siguientes:

(4) María compró una casa nueva.

(5) Fue MARÍA la que compró una casa nueva. 
Ambos enunciados transmiten una misma información, no obstante, en (5) la construcción fue MARÍA la que lleva nuestra atención a María: el emisor, por algunas razones, se decidió a subrayar esta parte del enunciado.

El mecanismo de focalización se apoya en numerosas estructuras lingüísticas que hacen hincapié en una determinada parte del texto. Estas estructuras pertenecen a diferentes niveles, como el semántico, el sintáctico o el prosódico. En el presente trabajo analizamos tres tipos de construcciones focalizadoras, esto es, el sujeto empírico yo, la repetición y el acento de insistencia. Hay que subrayar, sin embargo, que estos tres mecanismos no son los únicos que pueden desempeñar el papel de focalizador y que también otras estructuras pueden ser analizadas según el modelo propuesto.

Son dos los ámbitos que se suelen considerar afectados por la atenuación: el contenido proposicional del enunciado o la fuerza ilocutiva de lo dicho (Albelda - Cestero 2011: 13). En el presente trabajo introducimos la hipótesis según la cual la atenuación puede también extenderse a la estructura informativa del texto. Por lo tanto, la unidad base del nuestro análisis constituye la información. Nuestra hipótesis sostiene que, como se puede atenuar el contenido proposicional del enunciado, resulta posible atenuar alguna de las partes de la estructura informativa. En nuestra opinión, la atenuación de una información radica en la focalización de otra, como presenta el esquema:

La focalización: la INFO 1 llama la atención del destinatario

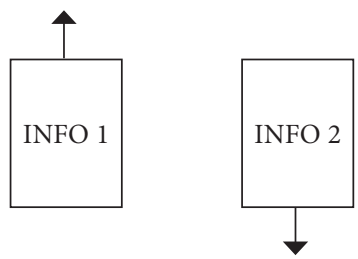

La atenuación: el emisor se distancia del INFO 2

La focalización se basa en una serie de mecanismos lingüísticos (de acuerdo con la propuesta de Fuentes Rodríguez, la Macroestrutura se apoya en la Microestructura, esto es, los mecanismos fonéticos, sintácticos y semánticos). Por eso, hemos analizado el corpus, primero, reconociendo los mecanismos lingüísticos que propician la focalización y segundo, observando cómo la focalización de una información atenúa la otra.

\section{La figura el destinatario}

Antes de empezar el análisis de determinados casos de focalización en los cuales se apoya el mecanismo de atenuación cabe resaltar que ambos fenómenos tienen un aspecto en común: la figura del destinatario. El destinatario es, en las palabras de Escandell (2008: 28-29), "la persona (o personas) a la(s) que el emisor dirige su enunciado y con la(s) que normalmente se suele intercambiar su papel en la comunicación de tipo dialogante". En ambas estructuras, tanto informativa como argumentativa, el papel del receptor resulta crucial a la hora de codificar y descodificar el mensaje hallado dentro del enunciado. 
Como indica Gutiérrez Ordóñez (2014: 16-19), el emisor al construir su enunciado tiene en cuenta el conocimiento previo del destinatario. De esta manera, la persona que crea el enunciado debe estimar cuál es la información ya conocida por su interlocutor y cuál sería la información nueva. De acuerdo con el supuesto conocimiento previo del destinatario, el hablante estructura su enunciado apoyándose en una serie de recursos lingüísticos. La atenuación también indica el interés por la figura del destinatario. Como ya hemos señalado, constituye una estrategia argumentativa, esto es, el proceso de exponer una serie de argumentos que incitan una cierta conclusión en el receptor (Fuentes Rodríguez - Alcaide 2007: 9-24). Por lo tanto, podemos ver claramente que la figura del interlocutor desempeña un papel esencial en la estructura argumentativa: es el destinatario quien se ve más influenciado por los recursos argumentativos.

La figura del destinatario es, desde nuestro punto de vista, la que, junto con la del emisor, condiciona la aparición del enunciado. En otras palabras, sin el destinatario no hay nadie a quien transmitir una información nueva, ni llevar a una conclusión determinada. Claro está, sin embargo, que el hecho de tener en cuenta al destinatario, no garantiza que el enunciado cumpla ni con su función informativa ni argumentativa. El emisor no siempre está totalmente seguro sobre cuál es el conocimiento previo de su interlocutor (Escandell 2008: 34), tampoco cuáles serán los argumentos adecuados para convencerlo de una determinada conclusión. No obstante, hay que subrayar que tanto en el proceso de focalización como de atenuación la figura del destinatario se nos presenta de mayor importancia.

\section{La intensificación}

Otro fenómeno relacionado con el presente artículo constituye el concepto de la intensificación. La intensificación, detenidamente analizada por Albelda (2005), puede aparecer en los ejemplos citados, sin embargo, no constituye el objetivo de nuestro estudio. La focalización, esto es, el relieve que se pone a una información concreta, puede apoyarse en unos procedimientos lingüísticos muy parecidos a los utilizados por la intensificación. Por eso, puede parecer que los ejemplos descritos demuestran el funcionamiento de la intensificación y no de la atenuación. Sin embargo, resulta de mayor entidad reconocer dos cuestiones:

- La focalización no es el sinónimo de la intensificación. El primer concepto pertenece al nivel informativo del texto y la unidad que maneja es la información. La intensificación, por su parte, es un fenómeno que puede modificar tanto el contenido preposicional del enunciado, como unos rasgos extralingüísticos en los que se desarrolla la conversación. Por lo tanto, aunque en muchos casos coinciden en los mecanismos lingüísticos, se trata de dos nociones distintas.

- Nuestra hipótesis supone que la focalización de una información puede constituir la atenuación de otra. De este modo, al focalizar la INFO 1 se atenúa la INFO 2. Aunque la focalización de la INFO 1 puede relacionarse con la intensificación de la INFO 1, el elemento que es susceptible de ser atenuado es la INFO 2. La relación entre la focalización de la INFO 1 y la intensificación puede ser objeto de otro estudio, no obstante, nuestro trabajo se ocupa más bien del vínculo entre la focalización de la INFO 1 y la atenuación de la INFO 2. 


\section{Las funciones atenuadoras}

Siguiendo las pautas del reconocimiento de la atenuación propuestas por Albelda y Briz (2013: 300-302), en el presente artículo optamos por la siguiente distribución de funciones atenuadoras:

- elemento desencadenante: la situación comunicativa

- el segmento atenuante: la información focalizada (INFO 1)

- el segmento atenuado: la información no focalizada (INFO 2)

El primer elemento, la situación comunicativa, resulta imprescindible, dado que los mecanismos lingüísticos adquieren su fuerza atenuadora solamente en contextos concretos. Como afirma Albelda (2010: 42):

El problema de la identificación de los enunciados atenuados estriba en que, a pesar de que sus formas y funciones se encuentran, con más o menos suerte, establecidas, la atenuación es una categoría pragmática y solo en su contexto real es posible identificarla. En este sentido, el analista que pretende identificar los casos de atenuación en un texto o en un discurso puede dudar al enfrentarse al texto desde fuera, como teórico y estudioso de un producto realizado por otros y en una situación ajena.

Por lo tanto, solamente en unas situaciones unos determinados medios lingüísticos actúan como atenuantes.

El elemento que propicia la aparición de la atenuación constituye, en nuestro caso, la situación comunicativa en la que se encuentran los hablantes. Albelda y Briz (2013: 293-295) afirman que la atenuación resulta más probable en las situaciones de menor coloquialidad (presentando a la vez los rasgos que sirven como marcas de coloquialidad). Aunque reconocemos la veracidad de los criterios mostrados, creemos que la atenuación constituye un mecanismo presente también en las conversaciones de características bien distintas. A lo largo de nuestro trabajo, hemos analizado conversaciones que se caracterizan por una serie de rasgos, entre las cuales encontramos los siguientes:

a) Todas las conversaciones constituyen las llamadas conversaciones coloquiales prototípicas, esto es, las que, según las indicaciones de Briz y Grupo Val.Es.Co (2002: 17-19), se caracterizan por: "una mayor relación de igualdad social y funcional, una mayor relación vivencial de proximidad, un marco de interacción familiar y una temática no especializada”. Claro está que en el ámbito familiar los hablantes pueden disfrutar de mayor libertad de expresión $y$, en consecuencia, prescindir de ciertos mecanismos que sirven para ocultar la verdadera intención del enunciado. No obstante, con los amigos o familiares se pueden debatir asuntos más controvertidos o delicados. Por eso, aunque se expresa la opinión más abiertamente, el empleo de ciertas estrategias atenuadoras resulta imprescindible: al fin y al cabo se evita ofender a los interlocutores que desempeñan un papel muy importante para el emisor del enunciado. 
b) La conversación tiene que llevar cierto matiz argumentativo. En otras palabras, los hablantes aportan unos argumentos que consideran oportunos para que sus interlocutores lleguen a unas conclusiones concretas. La dimensión argumentativa del texto obliga al emisor del enunciado a utilizar una serie de estrategias que favorecen la comprensión y la aceptación de sus argumentos por los demás. Por eso, el emisor recurre a unos procedimientos, entre ellos la atenuación, para aumentar la fuerza argumentativa de su enunciado.

c) El tema o los argumentos tienen que constituir una posible amenaza a la imagen del interlocutor (sobre el concepto de la imagen, vea Goffman 1959; Brown y Lewinson 1987), lo que se realiza de dos maneras. Primero, los hablantes pueden tener opiniones diversas acerca de un mismo asunto. En este caso, se aplican los mecanismos de atenuación con el objetivo de suavizar los argumentos, hacerlos menos directos. Por otra parte, existen también unos temas considerados delicados o tabúes en una determinada sociedad. Se trata de todo tipo de asuntos sociales, políticos, religiosos, morales o personales de los cuales no se suele hablar, o bien al introducirlos en el discurso hay que tener mucho cuidado. En varias ocasiones los hablantes no saben cuál es la postura de sus interlocutores acerca de uno de estos temas. Por eso, para no ofenderlos, aplican unos mecanismos atenuadores que sirven como señal de que, aunque se asume un punto de vista concreto, se sigue tolerante frente a otras posturas. En consecuencia, aunque la opinión presentada puede amenazar la imagen del destinatario, parece menos directa y su emisor más comprensible frente a las creencias de otras personas.

Entre otros componentes de la estrategia atenuadora encontramos el segmento atenuante y el segmento atenuado. El primero constituye, en nuestro caso, la información focalizada. Es el elemento que provoca el distanciamiento del emisor frente a lo que dice. El segundo viene representado por la información no focalizada. Es la información que, debido a la focalización de otra, queda en sombra, no se expresa directamente $y$, en consecuencia, se convierte en la información atenuada.

\section{El análisis}

Para apoyar nuestra tesis sobre la relación entre la focalización y la atenuación analizamos dos conversaciones coloquiales que cumplen con los tres requisitos de la situación comunicativa previamente expuestos, a saber, son conversaciones coloquiales prototípicas, el tema que abarcan suscita la dimensión argumentativa y entre los interlocutores existe un cierto grado de desacuerdo o, por lo menos, la posibilidad de que tengan opiniones distintas. Aunque el número de las conversaciones que tenemos en cuenta no es amplio, nos parece suficiente para presentar el funcionamiento de ciertos mecanismos (ya que estas dos conversaciones nos aportaron numerosos ejemplos que comprueban la tesis principal del presente trabajo). Las conversaciones que hemos analizado son las siguientes:

a) [ML.84.A.1] del Corpus de Conversaciones Coloquiales (2002: 72-80) de Antonio Briz y el Grupo Val.Es.Co. Constituye una riña entre novios, por lo que la dimensión argumentativa se manifiesta de modo muy visible. 
b) [L.15.A.2] del Corpus de Conversaciones Coloquiales (2002: 81-121) de Antonio Briz y el Grupo Val.Es.Co. Es una charla entre amigas que hablan de diversas cuestiones relacionadas con el sexo, la homosexualidad, el racismo, la tolerancia o la moralidad. Esta conversación nos ha aportado un amplio abanico de ejemplos por dos razones: primero, las amigas introducen temas bastante problemáticos analizados en función de diversos puntos de vista. Además, los participantes parecen no querer provocar la discusión, más bien intentan presentar su opinión de la manera menos ofensiva posible. Por eso, recurren a una serie de mecanismos de atenuación, entre los cuales hemos destacado los recursos focalizadores.

Aunque son solamente dos las conversaciones que analizamos, proporcionan un alto número de casos que convalidan nuestra hipótesis. Por eso, nos hemos limitado a presentar ejemplos provenientes solo de estos dos fragmentos ${ }^{2}$.

Teniendo en cuenta tanto la relación entre la Macro- y Microestructura propuestos por Fuentes Rodríguez (2015: 50-56), como los componentes del proceso de atenuación previamente expuestos, analizamos en adelante los diversos recursos lingüísticos que constituyen la base de la focalización de la INFO 1, lo que provoca la atenuación de la INFO 2. La unidad básica que manejamos es la información expresada mediante diversos medios lingüísticos.

\subsection{La focalización mediante el sujeto explícito yo}

La función sintáctica en español suele ser implícita. Esto significa que, debido a la morfología del verbo que nos aporta la información sobre la persona y el número gramatical, se emplea el llamado sujeto tácito (NGBLE 2011: 192). Como el sujeto explícito resulta optativo, su aparición en el enunciado suele llevar alguna finalidad. El sujeto explícito puede desempeñar unas funciones entre las cuales se enumeran la referencial, la social o la cohesiva (Muñoz 1988: 38). En cuanto a la aparición del sujeto en primera persona, puede tener carácter más específico, como afirma Calsamiglia (1996: 66): "The choice of 1P pronoun in Spanish as a marked use that creates effects of emphasis or intensification in order to express distinction or contraposition, uniqueness, emotion, involvement or personalization... Esto nos lleva a la conclusión de que, si el hablante se decide a marcar su presencia en el discurso, lo hace por una razón concreta.

Como señala Muñoz (1988: 40-41), el uso del pronombre suele cumplir dos objetivos: aportar un nuevo foco de atención o indicar un candidato entre una serie de elementos de la misma naturaleza. En otras palabras, al introducir el pronombre el hablante, o bien focaliza un aspecto, o bien lo distingue entre otros semejantes. Lehmann (2005: 136-137), por su parte, incluye el uso del sujeto explícito en italiano dentro de la categoría de pleonasmos de carácter gramatical, contrastándolo con su equivalente en francés (en el que el sujeto explícito es un elemento

2 En los fragmentos citados aparece una serie de signos que necesitan una breve explicación (Briz 2002: 29-30):

/,//,///: pausas,

$\uparrow, \downarrow, \rightarrow$ : entonación ascendente, descendente, mantenida,

$\$$ : $\quad$ sucesión inmediata entre dos emisiones de distintos interlocutores,

${ }^{\circ}()^{\circ}$ : $\quad$ pronunciación con una intensidad baja o próxima al susurro,

('): silencio. 
obligatorio de concordancia). Como en italiano el sujeto explícito resulta opcional, Lehmann concluye que su aparición desempeña la función de énfasis. Lo mismo podemos afirmar en cuanto al español: el hecho de marcar el sujeto (especialmente si este coincide con la figura del emisor del texto) en situaciones en las que el enunciado puede prescindir de este pronombre, parece constituir una representación lingüística del fenómeno de la focalización. Para comprobarlo, demostramos dos fragmentos de la conversación a) (riña entre novios).

(6) 141 B: \$por lo menos ahora $\downarrow$ si-/ si ahora tienes algún problema

142 pues vale $\downarrow$ pues no me lo demuestres// si- si- si tú ahora $\rightarrow$ si

143 yo no quiero agobiarTE/ yo no quiero que estés ahí dicéndo-

144 me te quiero todo el día $\rightarrow$ y que estés diciéndome cosas boni-

145 tas y todo ESO// pero- por lo menos si tienes un problema me

146 gustaría que confiaras en $\mathbf{m i} \downarrow$ ya como amiga/ ${ }^{\circ}$ (además que) ${ }^{\circ}$

147 es que no sé qué decirte $\downarrow^{\circ}$ (Andrés) ${ }^{\circledR}$

(7) 159 B: pero si yo no te pido más tiempo $\downarrow$ yo lo que te pido es que estés

160 SEGURO/ porque si no estás seguro pues/ oye $\downarrow$ si quieres lo

161 dejamos ¿me entiendes? yo no lo quiero dejar/ yo por mí ya

162 sabes que/ yo te quiero mucho y yo $\uparrow /$ o sea- si ya sabes que

163 por mí $\mathrm{NO} /$ pero si tú/ ves que necesitas un tiempo/ o- yo qué

164 sé o que no estás seguro de que me quieras $\rightarrow /$ o/ es que no lo

165 SÉ/ entonces ya eso es lo que tú pienses// yo por mí [ya]

Generalmente, el hablante B expresa dos informaciones:

INFO 1: El emisor B quiere mucho a su pareja y no tiene intención de dejarla.

INFO 2: La culpa de la discusión y de la posible terminación de la relación es de la pareja del emisor B.

Aunque son muchas las palabras y las oraciones que pronuncia el hablante, creemos que el contenido informativo de los fragmentos presentados se reduce a estas dos informaciones. Como podemos observar, el sujeto explícito yo aparece en los enunciados que trasmiten la INFO 1, lo que provoca su focalización. De este modo, lo que atrae nuestra atención es la INFO 1. Por lo tanto, la INFO 2 queda en sombra, se presenta menos visible, el emisor B se distancia de ella. Creemos, entonces, que la focalización de la INFO 1 atenúa la INFO 2 según el siguiente esquema:

\section{MICROESTRUCTURA}

Recurso lingüístico: $\longrightarrow$ el sujeto explícito yo

\section{MACROESTRUCTURA:}

INFORMACIÓN

La focalización de la INFO $1: \longrightarrow$

No es culpa del emisor
MACROESTRUCTURA:

ARGUMENTACIÓN

La atenuación de la INFO 2:

Es culpa del destinatario 
El análisis de (6) y (7) y las conclusiones que se sacan pueden parecer subjetivos por dos razones. Primero, el uso de los pronombres personales puede constituir un rasgo individual del hablante (formar parte de su idiolecto). Por otra parte, no se debe olvidar que el participante B puede simplemente matizar el contaste entre su comportamiento y el comportamiento de su pareja. Por eso, se presentan también los fragmentos de la conversación b) (charla entre amigas) con el objetivo de aclarar y consolidar nuestra interpretación del uso de este recurso lingüístico.

(8) $472 \quad$ L: ¿pero tú no lo haces $\downarrow$ ?

473 E: ipero yo no lo hago!/ o $\mathrm{s}(\mathrm{e}) \mathrm{a} \rightarrow /$ yo estoy pensando quién está

474 delante $\downarrow$ porque para mí hay cosas más importantes que pasar

475 una noche guay// y enrollarme con un tipo/// o sea $\rightarrow$ / yoo-yo

476 no $\downarrow$ verás- yo es que tengo muy claro con quién me voy a

477 enrollar/ para mí eso es muy- muy importante $\S$

(9) $770 \quad$ E: $\$[$ pero yo por ejemplo]

771 tengo problemas de cultura/ que sí que entiendo que- no debes

772 ser así pero lo soy/ no sé por qué/ yo por ejemplo- a mí me

773 repugna laa homosexualidad/ yo estoy totalmente en contra//

$774 \quad$ [pero no $(())=$ ]

En (8) y (9) estamos ante mecanismos de atenuación, pero un poco diferentes a los de (6) y (7). En ambos casos, el participante E repite varias veces el pronombre yo con el objetivo de subrayar que lo que expresa es su opinión personal, que no es una verdad general que debe ser asumida por toda la sociedad (aunque, en realidad, no está de acuerdo con las personas que presentan otro punto de vista). En (8) el hablante E manifiesta su postura frente a relaciones sexuales con personas desconocidas. Varias veces durante el discurso subraya que es ella a la que no le parece bien practicar sexo con hombres desconocidos. De este modo focaliza que es su propio punto de vista, que no lo quiere imponer a nadie más. No obstante, toda la conversación parece apuntar a que la cuestión no le parece tan indiferente: tantas veces subraya cuál es su postura al respecto que podemos sacar la conclusión de que tiene una opinión rotunda acerca de cómo uno debe comportarse en este tipo de situación.

Un ejemplo parecido lo encontramos en (9). El hablante habla de la homosexualidad recurriendo varias veces al pronombre yo, lo que sugiere que es su punto de vista particular y que no lo impone a nadie más. Por otra parte, en la misma intervención utiliza tales expresiones como a mí me repugna la homosexualidad o estoy totalmente en contra que parecen indicar que tiene una opinión tajante respecto a la homosexualidad y no acepta otra postura al respecto.

En ambos casos el proceso de atenuación se manifiesta de la siguiente manera: 


\section{MICROESTRUCTURA \\ MACROESTRUCTURA: INFORMACIÓN \\ MACROESTRUCTURA: \\ La focalización de la INFO 1: ARGUMENTACIÓN \\ Recurso lingüístico: todo lo dicho por el emisor es solo su punto de vista (no lo quiere imponer a nadie)

MACROESTRUCTURA:
ARGUMENTACIÓN
La atenuación de la INFO 2:
el emisor presenta una opinión
rotunda acerca de los temas
tratados

En todos los ejemplos presentados en este apartado, los hablantes al utilizar con abundancia el sujeto explícito yo llaman nuestra atención a ciertos aspectos de sus intervenciones que, en realidad, no constituyen el punto clave de todo el discurso: actúan como mecanismos de atenuación, gracias a las cuales se evita ofender a las personas que pueden no estar de acuerdo.

\subsection{La focalización mediante la repetición}

La repetición de los elementos léxicos en la conversación constituye un mecanismo bastante frecuente que puede ejercer varias funciones. Según Tannen (2007: 58-67), la repetición resulta muy útil en varias etapas: la producción, la comprensión, la conexión o la interacción. Camacho (2001), por su parte, afirma que:

La repetición hace preservar los referentes, mantiene el mismo grado de información y hace que los materiales lingüísticos implicados en dicho encadenamiento progresen temáticamente, en virtud de la conexión basada en relaciones intraoracionales y supraoracionales cercanas o bien más alejadas entre sí, en el seno de un contexto discursivo mayor.

En cuanto a la estructura informativa, Gutiérrez Ordóñez (2014: 37) considera la reduplicación de los elementos léxicos como uno de los mecanismos de la insistencia y, en consecuencia, de la focalización. El mismo hecho de repetir una expresión en el discurso llama la atención del oyente, por lo que el elemento reiterado destaca entre otros constituyentes del enunciado.

Como señala Garcés Gómez (2002-2004: 439-441), existen dos tipos de repeticiones: la autorrepetición, cuando el hablante repite sus propias palabras, y la heterorrepetición, cuando el hablante repite las palabras de su interlocutor. En ambos casos es posible utilizar este mecanismo con el objetivo de atenuar una información. Partimos con los ejemplos que constituyen casos de la auteorepetición.

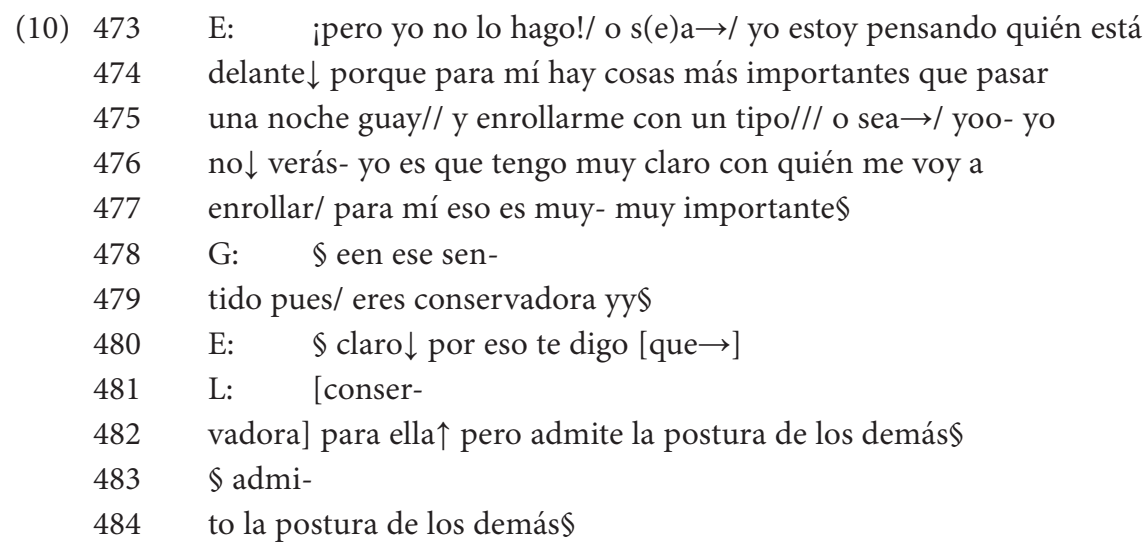




$\begin{array}{ll}485 & \text { L: } \quad \text { S entonces [noo eres=] } \\ 486 & \text { G: } \quad \text { [por eso] } \\ 487 & \text { L: }=\text { conservadora } \\ 488 & \text { G: ¡hombre! Dentro de lo que cabe para ella- para sí misma es } \\ 489 & \text { conservadora } \uparrow / y \text { para los demás oye } \downarrow \text { que cada cual haga lo que } \\ 490 & \text { quiera [con su vida] } \\ 491 & \text { E: } \quad \text { sí pero] no siempre } \downarrow \text { no va a ser tan- es que no se trata } \\ 492 & \text { de ser conservadora ni de na(da) } \downarrow \text { se trata simplemente } \rightarrow / \\ 493 & \text { oye } \downarrow \text { que cada uno viva su vida y punto/ yo soy muy demócra- } \\ 494 & \text { ta } \downarrow \text { mira// yo te voy a decir/ cada uno que viva su vida } \downarrow \text { yo no } \\ 495 & \text { tengo que arreglarle la vida a mi vecino } \uparrow \text { y punto } \downarrow \text { y ya está/ yy } \\ 496 & \text { bueno y mi vec- ya te digo } \downarrow \text { que mi vecino lleve su vida } \uparrow \text { y yo } \\ 497 & \text { llevaré la mía } \downarrow \text { y ya está } \downarrow \text { que sí } \downarrow \text { yo puedo posiblemente ser muy } \\ 498 & \text { amiga de mi vecino } \downarrow \text { aunque él tenga unas costumbres y unos } \\ 499 & \text { vicios y y tengo los míos/ pero no quita ¿entiendes? (pp. 93-94) }\end{array}$

Para detectar los mecanismos de atenuación hay que analizar la situación comunicativa. El fragmento constituye una intervención de la conversación entre amigas (b)) que hablan sobre relaciones sexuales. El emisor E se presenta en contra de las relaciones sexuales con personas desconocidas, pero en su última intervención suaviza su postura recurriendo a su supuesta tolerancia. De este modo, se nos muestran dos informaciones:

INFO 1: el emisor E se presenta tolerante frente a las decisiones de los demás;

INFO 2: el emisor E no acepta cierto tipo de comportamiento.

Como podemos observar, en la última intervención el emisor E repite varias veces dos conceptos: mi vecino y cada uno que viva su vida. Ambas expresiones se relacionan con la INFO 1, esto es, con la noción de tolerancia que se atribuye el emisor E a sí mismo. Así, no sería descabellado pensar que se focaliza la INFO 1, distanciándose de la verdadera intención comunicativa del hablante, esto es, transmitir la INFO 2 que nos informa sobre su postura más bien conservadora. Utilizando uno de los mecanismos de la focalización, el emisor del enunciado parece atenuar la información que puede suscitar polémica:

\section{MICROESTRUCTURA MACROESTRUCTURA:} INFORMACIÓN

Recurso lingüístico: la repetición de unos conceptos
La focalización de la INFO 1: El emisor es tolerante de comportamiento
MACROESTRUCTURA: ARGUMENTACIÓN

La focalización de la INFO 1:
El emisor es tolerante
de comportamiento

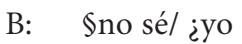

(11) 90 91 he hecho algo mal? estás- es por algo que yo $\rightarrow \bigotimes$

A: $\$ N O /$ si- yo sé

93 que el problema soy yo $\left(3^{\prime \prime}\right)$ 


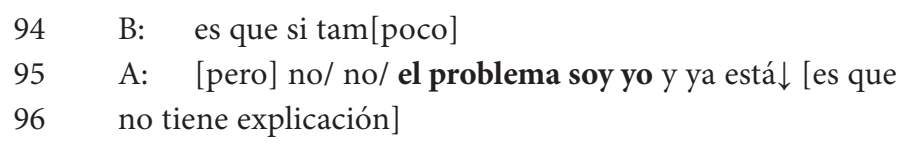

El ejemplo (11) proviene de la conversación a) (riña entre novios). El participante A repite sus propias palabras el problema soy yo que sugieren que él es el culpable de toda la situación. De este modo, la atenuación abarca dos cuestiones: primero, se suaviza toda la situación comunicativa en la que se encuentran los hablantes (que no es agradable para ninguno de los participantes). Además, en la parte posterior A dirige ciertas acusaciones hacia $\mathrm{B}$ (le dice que, en realidad, ella también tiene la culpa, porque no le deja llevar una vida social). Por lo tanto, la estructura informativa es la siguiente:

INFO 1: el emisor es el culpable por la situación;

INFO 2: la culpa es de ambas personas.

Estas informaciones se distribuyen de la manera siguiente:

$\begin{array}{lll}\text { MICROESTRUCTURA } & \begin{array}{l}\text { MACROESTRUCTURA: } \\ \text { INFORMACIÓN }\end{array} & \begin{array}{l}\text { MACROESTRUCTURA: } \\ \text { ARGUMENTACIÓN }\end{array} \\ \text { Recurso lingüístico: } \longrightarrow \begin{array}{l}\text { La focalización de la INFO 1: } \longrightarrow \begin{array}{l}\text { La atenuación de la INFO 2: } \\ \text { la repetición de unos } \\ \text { conceptos }\end{array} \\ \text { la culpa }\end{array} & \begin{array}{l}\text { Ambos participantes tienen } \\ \end{array}\end{array}$

El segundo caso constituye la llamada heterorrepetición, lo que ilustran los ejemplos (12) y (13):

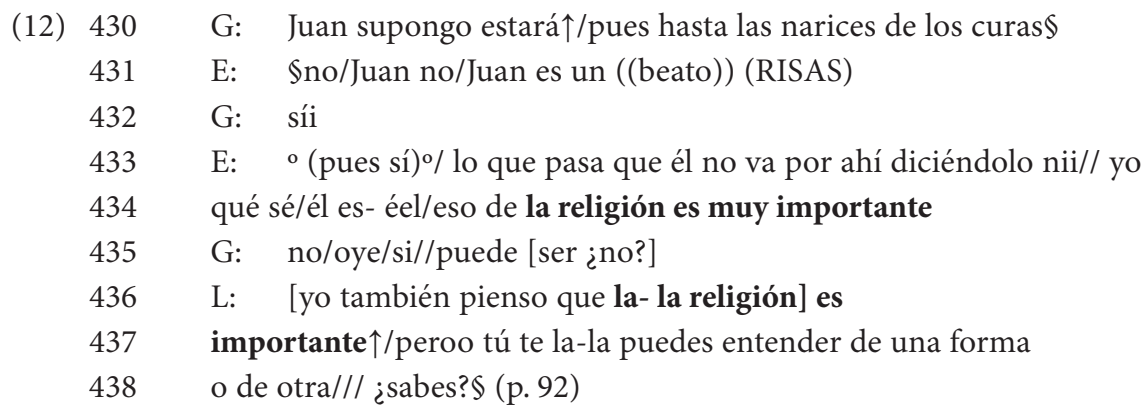

El fragmento proviene de conversación b) (charla entre amigas). Los hablantes reflexionan sobre Juan, el novio de E, que es muy religioso. El participante E sostiene que la religión constituye un aspecto muy importante en la vida, mientras que el hablante L, aunque no lo niega, quiere presentar otro cariz del mismo asunto. Para no amenazar a la imagen del interlocutor E, presenta dos informaciones: 
INFO 1: la religión es importante;

INFO 2: la religión, tal como la percibimos tradicionalmente, tiene sus desventajas.

La INFO 1 es una repetición de lo que dice el participante E. De este modo, estamos ante la heterorrepetición que focaliza la INFO 1. Resulta factible que, al llamar la atención a la INFO 1, se atenúa lo que en realidad constituye la finalidad de esta intervención, esto es, la transmisión de la INFO 2, según el modelo:

$\begin{array}{lll}\text { MICROESTRUCTURA } & \begin{array}{l}\text { MACROESTRUCTURA: } \\ \text { INFORMACIÓN }\end{array} & \begin{array}{l}\text { MACROESTRUCTURA: } \\ \text { ARGUMENTACIÓN }\end{array} \\ \text { Recurso lingüístico: } \longrightarrow \begin{array}{l}\text { La focalización de la INFO 1: } \\ \text { la repetición de la } \\ \text { expresión introducida }\end{array} & \begin{array}{l}\text { La atenuación de la INFO 2: } \\ \text { el destinatario }\end{array} & \begin{array}{l}\text { El emisor presenta otro punto } \\ \text { de vista que el destinatario }\end{array}\end{array}$

(13) $87 \quad$ B: $\quad$ yo creo que no vamos bien porque tú no quieres $\$$

$88 \quad \mathrm{~A}: \$ \mathrm{PERO} \rightarrow / /$

89 PORQUE- PORQUE YO NO QUIERO/ ¡bah!// mira $\$$

En (13) estamos ante un fragmento de la conversación a) (riña entre novios). El participante B subraya que es A quien no quiere continuar la relación. El hablante A no está de acuerdo, sin embargo, repite las palabras de B (incluso reforzándolas mediante la entonación). Detectamos en esta intervención cierto matiz irónico, lo que sugiere que A no está de acuerdo con las palabras repetidas y cree que B no tiene razón, aunque no lo menciona explícitamente.

INFO 1: el emisor no quiere continuar la relación con el destinatario;

INFO 2: el emisor quiere continuar la relación con el destinatario (el destinatario no tiene razón).

\section{MICROESTRUCTURA}

Recurso lingüístico:

la repetición de la expresión introducida

por el destinatario
MACROESTRUCTURA: INFORMACIÓN

La focalización de la INFO 1:

El emisor no quiere continuar la relación
MACROESTRUCTURA: ARGUMENTACIÓN

La atenuación de la INFO 2:

El destinatario no tiene razón

\subsection{La focalización mediante el acento de insistencia}

La prosodia constituye uno de los factores de mayor importancia a la hora de organizar el discurso oral (Dorta 2008: 119). Los rasgos prosódicos marcan no solo la actitud del hablante frente a lo que dice, sino que también pueden demostrar la organización informativa del discurso. Como indica Alonso-Cortés (2015: 263), entre los diferentes elementos prosódicos encontramos el acento frástico, esto es, una categoría que destaca una determinada palabra (o unas determinadas palabras) de la frase. De este modo, el acento frástico puede constituir 
uno de los mecanismos de la focalización. Gutiérrez Ordóñez (2014: 36) menciona este fenómeno bajo el nombre acento de insistencia, que, según el lingüista: "Es una sobrecarga energética que afecta a un segmento con el fin de subrayar su oposición a otro elemento generalmente más esperado". Cantera et al. (2005: 4-5) advierten, además, que el foco puede abarcar tanto una palabra determinada, como todo el enunciado.

Existen numerosos estudios que examinan la relación entre el foco y los rasgos tonales o melódicos. Güemes et al. (2016) investigan si los hablantes pueden reconocer el foco solamente por los rasgos prosódicos. Face (2002), por su parte, estudia la relación entre el foco y la altura tonal. También Cabrera y Dorta (2015) se interesan por esta cuestión proponiendo un análisis de la variedad del español de la Gomera en las Islas Canarias. De estos estudios sacamos la conclusión de que los hablantes focalizan algún fragmento de su enunciado recurriendo a varios rasgos prosódicos. En el presente trabajo utilizamos el término acento de insistencia teniendo en cuenta que es una expresión muy generalizadora, porque en diferentes ocasiones puede significar mecanismos tonales o melódicos distintos.

Como en previos casos, el acento de insistencia puede destacar una información con el objetivo de atenuar otra. El corpus que hemos analizado se compone de conversaciones orales, sin embargo todas vienen transcritas de modo que no podemos escuchar directamente cuáles son sus rasgos prosódicos. No obstante, en todas las conversaciones los transcriptores marcaron en mayúscula lo que en la introducción denominan "pronunciación marcada o enfática". Gracias a eso, hemos podido analizar no solo los recursos sintácticos o semánticos, sino también los fónicos. En resultado, hemos encontrado intervenciones en las que reconocemos mecanismos focalizadores de finalidad atenuadora. En el fragmento proveniente de la conversación a) (riña entre novios) ha llamado nuestra atención el ejemplo siguiente:

$\begin{array}{ll}\text { (14) } 181 & \text { A: no si/ TÚ NO TE HAS PORTADO MAL// pero } \rightarrow \text { no lo sé/ hay } \\ 182 & \text { veces que - que me da la impresión de que/cuando estoy con } \\ 183 & \text { mis amigos me-/ me miras como si me dijeras ¿por qué estás } \\ 184 & \text { ahí?/ ¿sabes? (p. 77) }\end{array}$

En la intervención presentada hemos detectado dos informaciones:

INFO 1: el destinatario no tiene la culpa;

INFO 2: al destinatario no le gusta cuando su pareja queda con sus amigos.

Al cambiar la entonación, el emisor A llama la atención a la INFO 1. Por lo tanto, se intenta atenuar lo que realmente constituye la información nueva y el propósito de esta intervención, esto es, la INFO 2, según el esquema:

$\begin{array}{ll}\text { MICROESTRUCTURA } & \begin{array}{l}\text { MACROESTRUCTURA: } \\ \text { INFORMACIÓN }\end{array} \\ \text { Recurso lingüístico: } \longrightarrow \begin{array}{l}\text { La focalización de la INFO 1: } \\ \text { el emisor no atribuye la culpa } \\ \text { la entonación }\end{array} & \text { al destinatario }\end{array}$

MACROESTRUCTURA: ARGUMENTACIÓN
$\longrightarrow$ La atenuación de la INFO 2: el comportamiento del destinatario también provoca problemas


En cuanto a la conversación b) (charla entre amigas), destacan los fragmentos (15), (16) y (17):

$\begin{array}{ll}401 & \text { E: } \quad \text { [es que-/ es que ee] } \\ 402 & \text { yo para mí } \uparrow \text { el hecho de ser conservadores y taal/ precisamen- } \\ 403 & \text { te radica en sus principios/y para mí } \uparrow \text { hay unas- unos valores// } \\ 404 & \text { muy fundamentales que a lo mejor para otra persona no lo son } \\ 405 & \text { ¿no? /// }\left(3^{\prime \prime \prime}\right) \text { no [sé] } \\ 406 & \text { G: [bueno la cues-] la cuestión es que antes eras } \\ 407 & \text { un poquito BEATA } \uparrow / \mathrm{y} \text { a(ho)ra/ lo eres menos ¿no?§ }\end{array}$

En general, esta parte de la conversación concierne la actitud del participante E sobre los valores que defiende. E mantiene que no le interesa lo que hacen los demás, por lo que G la llama liberal. No obstante, E no se percibe a sí misma como una persona liberal, más bien conservadora, con lo que G no está de acuerdo: cree que la postura de E es liberal. De este modo, así se distribuye la información en la intervención de G:

INFO 1: el destinatario solía ser una persona beata (lo que se vincula a la postura conservadora y no liberal);

INFO 2: para el emisor, el destinatario es una persona liberal.

No sería descbellado pensar que, subrayando la palabra beata que se relaciona con la postura conservadora, el emisor hace hincapié en una información que, en realidad, entra en oposición con lo que de verdad tiene en mente, como demuestra el esquema:
MICROESTRUCTURA
MACROESTRUCTURA: INFORMACIÓN
MACROESTRUCTURA:
Recurso lingüístico:
La focalización de la INFO 1:
la entonación el destinatario fue una persona beata (conservadora) ARGUMENTACIÓN
La atenuación de la INFO 2: el destinatario es una persona liberal

En los fragmentos siguientes, los hablantes hablan de la libertad en las relaciones sexuales. A lo largo de la conversación los participantes subrayan dos hechos: primero, que no practicarían sexo con personas desconocidas, y segundo, que no les interesa lo que hacen los demás al respecto.

(16) 505 L: $\quad$ a lo mejor algún día $\uparrow$ te da locura y lo haces $\$$

506 E: \$pero sí ES

$507 \quad$ VERDAD $\downarrow$ YO NO DIGO QUE NO/ a lo mejor me da ahora

508 mismo por cambio de [pensar=]

Aunque E parece tener una postura clara acerca de las relaciones sexuales con personas desconocidas, para resultar menos categórica atenúa su intervención focalizando mediante el acento de insistencia la posibilidad de cambiar de opinión. 
INFO 1: el emisor se presenta capaz de mantener relaciones sexuales con personas desconocidas;

INFO 2: el emisor está en contra de mantener relaciones sexuales con personas desconocidas.

La focalización de la INFO 1 provoca que el participante E se distancie de su verdadera postura respecto el tema discutido, según el esquema:

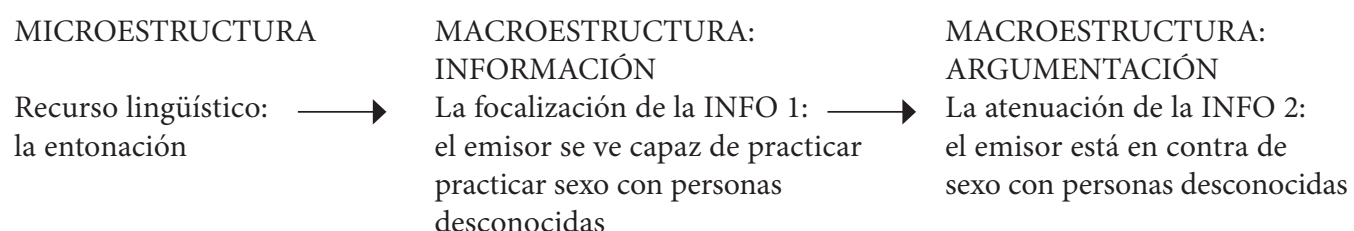

(17) 581 L: = no/era una chica de quinto/ a mí la verdad es que me impor-

582 taba muy poco lo que ella hiciera $\downarrow$ ME DABA igual ¿no? Lo que

583 pasa que me quedé $\uparrow /$ un poco e piedra $\downarrow$ pero es que $\rightarrow / /$ yo

584 me quedé de piedra porque es que ((me sentó mal)) /// una

585 noche $\uparrow /$ conocimos a unos tíos ¿no? y había unoo entre ellos

586 que estaba pues el chico bastante bien ¿no? Hab- no había

587 ninguno así que estuviera muy mal $\downarrow$ ¿no? Pero había uno que

588 es- que estaba mejor que los demás $\downarrow$ y entonces nos fuimos

589 con ellos después de que tocara la tuna $\uparrow^{\circ}($ nos fuimos con

590 ellos a un bar) \%//donde tocaban también/// estuvimos allí con

591 ellos en el bar y tal/// y luego nos fuimos a un paf//eso era las

592 tres de la mañana por lo menos ¿no? (p. 96)

El participante L también se presenta en contra de las relaciones sexuales con personas desconocidas. No obstante, atenúa esta postura subrayando que le da igual lo que hacen los demás (aunque, en realidad, tiene una opinión concreta al respecto).

INFO 1: no le interesan las decisiones y el comportamiento de los demás (es tolerante);

INFO 2: está en contra de las relaciones sexuales con personas desconocidas.

Como observamos, el acento de insistencia cae sobre la expresión me da igual que expresa la INFO 1. De este modo, se distancia de la INFO 2 que claramente demuestra una actitud opuesta a la información focalizada, pero que necesita atenuación porque puede ofender a otras personas. El esquema se estructura de modo muy parecido al caso precedente:

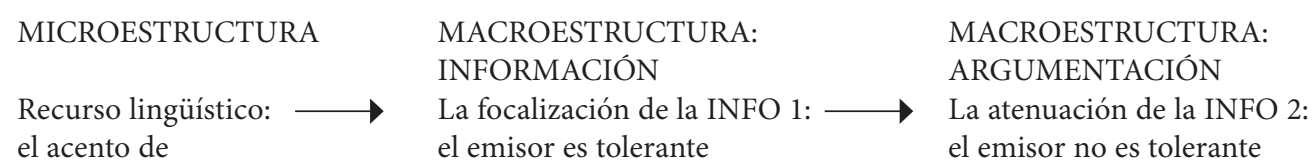

insistencia 


\section{Conclusiones}

A lo largo del presente artículo hemos analizado los diferentes casos de la focalización como mecanismo atenuador. Creemos que del mismo modo que se puede atenuar una expresión a nivel semántico, resulta posible atenuar una unidad de naturaleza bien distinta, esto es, la información. El mecanismo estudiado que reconocemos como una de las estrategias de la atenuación constituye la focalización. Los hablantes al focalizar una información se distancian de otra atenuándola. Así, la información que, por algunas razones, puede ejercer influencia negativa sobre la relación entre los hablantes, queda menos visible y, en consecuencia, se evitan situaciones conflictivas.

La posibilidad de existir la relación entre la focalización y la atenuación viene atribuida al modelo de Lingüística Pragmática de Fuentes Rodríguez (2015). Consideramos estos dos fenómenos como partes de dos Macroestructuras, la informativa y la argumentativa, entre las cuales se encuentran varios vínculos. Como los elementos de la Macroestructura se representan mediante mecanismos lingüísticos (la Microestructura), en el presente trabajo hemos estudiado distintos medios lingüísticos que se consideran propios para el fenómeno de la focalización, y, en este caso, llevan a la atenuación de determinadas informaciones.

Con el objetivo de llevar a cabo este análisis hemos examinado dos conversaciones coloquiales. Aunque se suele atribuir la atenuación a las conversaciones más bien formales con menor grado de familiaridad entre los participantes, hemos descubierto que también en el caso de las conversaciones muy informales, entre personas muy cercanas, se atenúan informaciones. Si el tema que se abarca suscita la polémica o los interlocutores no están de acuerdo entre sí, para no provocar conflictos, focalizan informaciones que no pueden ofender a los demás, ocultando de esta manera la información que constituye un verdadero aporte informativo.

La última observación que creemos importante destacar trata de la importancia de la atenuación en la sociedad. Es una estrategia que no solamente nos permite reforzar unos argumentos para que los destinatarios lleguen a una conclusión concreta, sino que también desempeña un papel significativo a la hora de establecer y mantener relaciones con otras personas. Gracias a la atenuación se les brinda la posibilidad a los hablantes de expresar sus opiniones, a veces muy tajantes, sin ofender a los que no comparten el mismo punto de vista. Por eso, el estudio de los mecanismos que constituyen la base de la estrategia atenuadora nos resulta de mayor entidad.

\section{Referencias bibliográficas}

Albelda Marco, M. (2005). La intensificación en el español coloquial. Valencia: Universitat de Valencia, Servei de Publicacions.

. (2010). ¿Cómo se reconoce la atenuación? Una aproximación metodológica basada en el español peninsular hablado. In F. Orletti, \& L. Mariottini (Eds.), (Des)cortesía en español (pp. 41-70). Roma: Università Roma Tre. 
Albelda Marco, M.; \& Briz Gómez, A. (2013). Una propuesta teórica y metodológica para el análisis de la atenuación lingüística en español y portugués. La base de un proyecto común. Onomázein, 28, 288-319.

Albelda Marco, M.; \& Cestero Mancera, A. (2011). De nuevo, sobre los procedimientos de atenuación lingüística. Español actual: Revista de español vivo, 96, 9-40.

Alonso-Cortés, Á. (2015). Lingüística. Madrid: Cátedra.

Asociación de Academias de la Lengua Española. (2011). Nueva gramática básica de la lengua española. Barcelona: Espasa.

Briz Gómez, A. (2003). La estrategia atenuadora en la conversación cotidiana española. In D. Bravo (Ed.), Actas del Primer Coloquio del Programa EDICE (pp. 17-46). Estocolmo: Universidad de Estocolmo.

Briz Gómez, A.; \& Grupo Val.Es.Co. (2002). Corpus de conversaciones coloquiales. Madrid: Arco/Libros.

Brown, P.; \& Levinson, S. (1987). Politeness. Some Universals in Language Use. Cambridge: Cambridge University Press.

Calsamiglia Blancafort, H. (1996). Multifaceted Dimensions of Self-reference. Links \& Letters, 3, 61-76.

Camacho Adarve, M. (2001). La repetición en el discurso oral. Tonos digital: Revista electrónica de estudios filológicos, 2.

Cantero, F.; Alfonso, R.; Bartoli, M.; Corales, A.; \& Vidal, M. (2005). Rasgos melódicos de énfasis en español, Phonica, 1, 1-40.

Díaz Cabrera, Ch.; \& Dorta Luis, J. (2015). Acentos tonales y variantes: declarativas en habla formal y espontánea de la Gomera (Islas Canarias). ELUA, 29, 53-80.

Dorta Luis, J. (2008). La focalización prosódica: funcionalidad en los niveles lingüístico y pragmático. Estudios de fonética experimental, 17, 105-138.

Escandell Vidal, M. (2008). Introducción a la Pragmática. Barcelona: Ariel.

Face, T. (2002). El foco y la altura tonal en español. Boletín de Lingüística, 17, 30-52.

Fernández Lorences, T. (2010). Gramática de la tematización en español. Oviedo: Universidad de Oviedo.

Fuentes Rodríguez, C. (2015). Lingüistica pragmática y Análisis del discurso. Madrid: Arco/Libros.

Fuentes Rodríguez, C.; \& Alcaide Lara, E. (2007). La argumentación lingüística y sus medios de expresión. Madrid: Arco/Libros.

Garcés Gómez, P. (2002-2004). La repetición: formas y funciones en el discurso oral. Archivo de filología aragonesa, 59-60, 437-456.

Goffman, E. (1959). The Presentation of Self in Everyday Life. New York: Doubleday.

Güemes, M.; Sampedro, B.; Cossio-Mercado, C.; \& Guerlekian, J. (2016). La relación entre foco y prosodia: análisis de la percepción de las prominencias acentuales en un corpus del español de Buenos Aires. Estudios de Lingüistica Universidad de Alicante, 30, 129-139.

Gutiérrez Ordóñez, S. (2014). Temas, remas, focos, tópicos y comentarios. Madrid: Arco/Libros.

Lehmann, C. (2005). Pleonasm and hypercharacterization. In G. Booij, \& J. van Marle (Eds.). Yearbook of Morphology (pp. 119-154). Heidelberg: Springer.

Muñoz, C. (1988). La presencia obligatoria del sujeto pronominal en inglés y en castellano. ATLANTIS, $1-2,37-44$

Rodríguez Ramalle, T. (2005). Manual de sintaxis de español. Madrid: Castalia.

Rojo, G. (1983). Aspectos básicos de sintaxis funcional. Málaga: Librería Ágora.

Tannen, D. (2007). Talking voices. Repetition, Dialogue, and Imagery in Conversational Discourse. Cambridge: Cambridge University Press. 